\title{
Increased caspase-3-dependent spermatogenic cell death and dysregulated adult spermatogenesis following in utero, lactational and direct exposure to para-nonylphenol
}

\author{
Leon M. McClusky ${ }^{1,}$ Christiaan de Jager $^{2}$ and Maria S. Bornman ${ }^{3}$ \\ ${ }^{1}$ Department of Physiology, University of Pretoria, South Africa \\ ${ }^{2}$ School of Health Systems and Public Health, University of Pretoria, South Africa \\ ${ }^{3}$ Department of Urology, University of Pretoria, South Africa
}

\section{Abstracts of the EUROTOX 2006/6 CTDC Congress - 43rd Congress of the European Societies of Toxicology \& 6th Congress of Toxicology in Developing Countries}

Germ cell development in the testis occurs in the context of a complex three-dimensional relationship with the supporting intratubular Sertoli cells, which are often the targets of environmental toxicants. One such a toxicant is the alkylphenolic compound, para-nonylphenol ( $p$-NP). We previously showed that $p$-NP reduced several testicular morphometric parameters, including sperm counts. The present study reexamined material collected in that study and set out to determine the site(s) of $p$-NP action and the processes targeted. Seven-day pregnant Sprague-Dawley rats were treated with either vehicle, 100 or $250 \mathrm{mg} / \mathrm{kg} p$-NP through gestation, lactation and afterwards directly to all male ( $n=20$ /group) off-spring until 10 weeks of age. At necropsy, the testes and epididymi were fixed in Bouin's fluid and embedded in paraffin wax. Paraffin sections of 10 testes from each group were dewaxed, rehydrated, and processed for terminal deoxynucleotidyl transferase-mediated dUTP nick end-labelling (TUNEL) and cleaved caspase-3 (Cell Signaling Technology, Beverly, MA, USA) immunohistochemistry (IHC) using a rabbit polyclonal at a 1:100 dilution. Both doses of $p$-NP significantly $(P<0.02)$ increased the number of TUNEL-positive germ cells. However, TUNEL-labelling was selective, and excluded labelling of basal cells with apoptotic morphology. Cleaved caspase-3 IHC strongly labelled basal cells (spermatogonia and early spermatocytes) with condensed chromatin, but not degenerate germ cells at intermediate positions in epithelium. Only the caspase-index of the $100 \mathrm{mg} / \mathrm{kg} p$-NP group was significantly $(P<0.05)$ three fold greater than controls. Both doses of $p$-NP significantly $(P=0.0011)$ increased the frequencies of stages IV-VI, whereas those for stages VII-VIII were significantly $(P<0.05)$ reduced in the $250 \mathrm{mg} / \mathrm{kg}$ group, and those of stages late VIII-IX (spermiating and recently spermiated tubules) were significantly $(P<0.01)$ reduced by 1.6 fold in the $100 \mathrm{mg} / \mathrm{kg}$ group. Thus, $p$-NP, a waterborne xenoestrogen, insidiously alters spermatogenesis in male offspring. 